Report of the

\title{
ARI Delegation to Japan on Alternative Refrigerants
}

February 1993 


\section{TABLE OF CONTENTS}

I. EXECUTIVE SUMMARY $\ldots \ldots \ldots \ldots \ldots \ldots \ldots \ldots \ldots$

II. OVERVIEW OF JAPANESE PHASE-OUT STRATEGIES $\ldots \ldots \ldots \ldots$

III. NEW REFRIGERANTS RESEARCH $\ldots \ldots \ldots \ldots \ldots \ldots \ldots$

IV. LUBRICANTS RESEARCH $\ldots \ldots \ldots \ldots \ldots \ldots$

V. MATERIAL COMPATIBILITY \& $\ldots \ldots \ldots \ldots \ldots$ LUBRICITY SCREENING

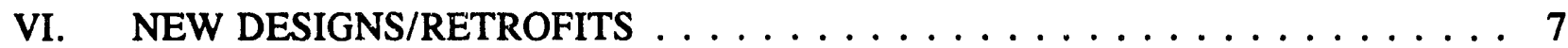

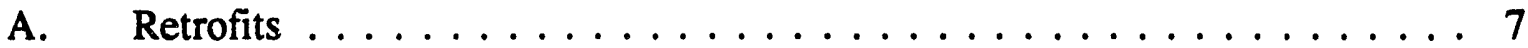

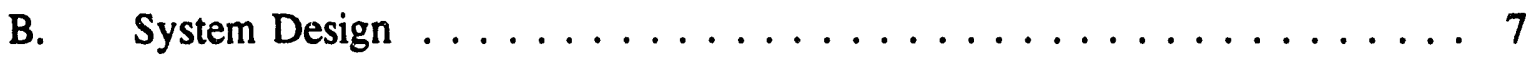

VII. OTHER OBSERVATIONS $\ldots \ldots \ldots \ldots \ldots \ldots \ldots \ldots$

VIII. $\quad$ REFERENCES $\ldots \ldots \ldots \ldots \ldots \ldots \ldots \ldots$

\section{APPENDIX A}

Proceedings, International Seminar on New Technology of Alternative Refrigerants Lubricants and Materials Compatibility, (February 8-10, 1993, Keidanren Hall, Tokyo) Japan Association of Refrigeration, pp. VI-VIII.

\section{APPENDIX B}

List of ARI Delegation

List of Companies Vicitar

\section{DISCLAIMER}

This report was prepared as an account of work sponsored by an agency of the United States Government. Neither the Umited States Government nor any agency thereof, nor any of their employees, makes any warranty, express or implied, or assumes any legal liability or responsibility for the accuracy, completeness, or usefulness of any information, apparatus, product, or process disclosed, or represents that its use would not infringe privately owned rights. Reference herein to any specific commercial product, process, or service by trade name, trademark, manufacturer, or otherwise does not necessarily constitute or imply its endorsement, recommendation, or favoring by the United States Government or any agency thereof. The views and opinions of authors expressed herein do not necessarily state or reflect those of the United States Government or any agency thereof. 


\section{EXECUTIVE SUMMARY}

In February 1993 a delegation of researchers from ARI member companies spoke at the International Conference on Alternative Refrigerants in Tokyo and visited several Japanese organizations for the purpose of exchanging information on alternative refrigerants. The specific purpose of the meetings was to review the methods being utilized to screen alternatives to CFCs and HCFCs: materials compatibility screening methods, lubricant testing techniques, as well as flammability studies. A list of papers presented at the conference are reproduced in Appendix A. Proceedings have been printed and selected papers are available through the ARTI Refrigerant Database (See Reference 1).

Members of the ARI delegation and the eight organizations visited are listed in Appendix B. A list of 41 questions covering phaseout strategies, niew lubricants, materials compatibility and other issues were sent in advance of the visit to the host companies.

Japanese companies seem to be focusing their efforts on changing over to CFC alternatives. The leading replacement refrigerant is HFC-134a. While not as much effort seems to be directed into finding alternatives to HCFCs, some companies stated that they plan to move away from HCFC equipment by 2000 . Refrigerant producers gave no indication that they would speed up refrigerant phaseout.

Equipment manufacturers are interested in finding single component or azeotrope replacements to HCFC-22. However, attention is currently focused on the zeotropic blend of $32 / 134 a(30 \% / 70 \%)$ as a substitute for HCFC-22. Unlike the U.S. tests, the Japanese tests indicaie that this blend is not flammable. These tests were run at different conditions than the tests in the U.S. and so led to different results. There is a need to standardize flammability testing methods. The delegation found that activities to investigate R-502 substitutes in Japan parallel those in the U.S. MITI has synthesized about 50 new compounds that are being investigated as possible third generation replacement refrigerants.

Polyalkylene glycols (PAGs) are currently used with HFC-134a in automotive airconditioning systems in Japan. Polyolesters (POEs) are the preferred synthetic lubricants for HFC refrigerants for all other applications. There were no reported research efforts to use hydrocarbon lubricants with HFC refrigerants.

Japanese air conditioning and refrigeration equipment manufacturers conduct materials compatibility and thermal stability tests which, in general, are the same as are commonly used by U.S. manufacturers. Several types of tests are used to determine the lubricity of refrigerant-lubricant mixtures including the Falex-pin and vee block tests as well as the Four Ball test. These devices are used by the Japanese for fundamental studies that led to improvements in lubricants, additives and materials. Japanese manufacturers rely 
on compressor tests at accelerated conditions of higher pressures and temperatures for final qualification of materials and lubricants.

Japanese companies seem more likely to recommend replacement of equipment rather than retrofit to alternaiive refrigerants. Gas-fired absorption is being pushed as an option. The JRAIA has published a guideline for conversions of centrifugal chillers from CFC-11 to HCFC-123. Recovery of refrigerants is not mandatory at this time, although it is becoming common practice. There is no Japanese standard for the purity level of reclaimed refrigerant.

\section{OVERVIEW OF JAPANESE PHASE-OUT STRATEGIES}

The Japanese air-conditioning equipment manufacturers visited are committed to phasing out CFC refrigerants by the end of 1995 . Some manufacturers have already changed to HCFC-22 or HFC-134a for CFC-12 applications and to HCFC-123 for CFC-11 applications. Several of them are planning to phase out of HCFCs around the year 2000 . They are basing their choices for replacement refrigerants on the following priorities:
A. Zero ODP
B. Low TEWI and low GWP with TEWI being more important
C. Non-flammability
D. Low toxicity

To reach these goals the application of hydrochlorofluorocarbons (HCFCs) is recognized by many companies as a legitimate interim solution. However, there is an undercurrent of concern in Japan that the HCFC phaseout dates proposed at the Copenhagen meeting in November of 1992 will eventually be moved up. Therefore, some companies are targeting to phase out of HCFC-22 for original equipment by as early as 2000 . Others plan to phase out HCFC-22 later in the following decade. The leading manufacturers of low pressure centrifugal chillers plan to use HCFC-123 through 2020, unless the phaseout date is moved forward.

Complicating the issue for Japanese manufacturers is the recent Ministry of Construction guideline (10/92) suggesting that HCFC's not be used, but rather either absorption or HFC equipment should be installed. The HCFC restriction applies primarily to large chillers. Packaged air-conditioning is currently excluded from this restriction. The guideline is being opposed by manufacturers and the Ministry of International Trade and Industry (MITI). 
The leading candidate to achieve zero ozone depletion is HFC-134a and products using HFC-134a are available in Japan now. Applications include transport refrigeration, HFC-134a in scroll compressors with liquid injection and centrifugal compressors in the lower tonnage ranges. The Japanese auto industry has implemented HFC-134a in many models through 1992 and will be in full scale production in 1994.

A single component refrigerant is preferred as a replacement for HCFC-22, an azeotrope is the second choice and zeotropic blends are least preferred. Zeotropic blends will probably have fractionation problems with mini-split systems with multiple evaporators. This type of system is very popular in Japan. These systems currently use HCFC-22 arid there is interest in using the azeotrope HFC-32/HFC-125 in new designs, especially for split systems.

The refrigerant producers generally were very familiar with the AREP program and seemed to be following the lead of the equipment manufacturers. Refrigerant manufacturers stated that they will produce CFCs and HCFCs as long as they are allowed under the phase out regulations and as long as their customers want them.

All the refrigerant producers are commercially producing HFC-134a and one is also producing HCFC-123. Although none are commercially producing HFC-125 or HFC$143 \mathrm{a}$ all indicated that they would produce them if demand developed. Several have pilot plants producing small quantities of HFC-32, HFC-125 and HFC-143a. All producers believed that they would produce the same blends with several compositions as demanded by their customers.

\section{NEW REFRIGERANTS RESEARCH}

Research in Japan into alternatives to HCFC-22 and R-502 is focused primarily on HFC$134 \mathrm{a}$ and the second generation HFC-32, HFC-125 and HFC-143a as mixture components. Although HFC-134a is being pursued as a potential alternative to HCFC-22 in some equipment, its performance in multi-zoned ductless splits (high volume product) with high refrigerant line pressure drops is not very attractive. Therefore, the focus had been on HFC-32 based mixtures which have similar volumetric capacities and pressures to HCFC-22. In the mixtures category the composition receiving most attention has been the zeotropic blend of $32 / 134 a(30 \% / 70 \%)$. In general, the Japanese equipment manufacturers are conducting very detailed and thorough assessments of these blends and are not convinced at this point that they offer a true alternative opportunity. For example, early testing of zeotropic blends on split systems, with one outdoor unit feeding multiple indoor units has shown erratic system operation due to what is thought to be composition shift. In some heat pump testing, frosting of the outdoor coil has been observed at significantly higher outdoor temperatures with zeotropic blends than with HCFC-22. Because of these problems with the binary blends, most Japanese 
manufacturers are less inclined to explore the zeotropic ternaries, such as $32 / 125 / 134 a$, than are their U.S. counterparts.

Research into R-502 substitutes is following along the same direction as U.S. and European manufacturers' efforts with various combinations of HFCs 32, 125 and 143a, but no firm commitments have been made to any of these blends by Japanese equipment manufacturers. This again reflects the very conservative approach being followed by the Japanese air-conditioning industry in the area of blends. Fin additional factor is the very restrictive Japanese high-pressure law that could preclude the use of some HFC blends.

Two issues that surfaced regarding HFC blends were flammability and refrigerant properties. There is a difference of opinion between Japan and U.S. chemical producers on the flammability envelopes of zeotropic blends such as HFC-32/HFC-134a $(30 \% / 70 \%)$. Some U.S. producers believe that mixture to be flammable, while some Japanese producers believe it to be non-flammable. Discussion of this issue indicated a need for international standardization on establishing flammability characteristics. In the case of refrigerant properties, there was concern expressed by several equipment manufacturers and the academia that there was no reliable refrigerant properties standard established in Japan for blends. The same problem exists in the U.S. in that properties from government agencies and chemical producers do not agree. A few Japanese equipment producers have begun to develop their own properties information for particular blends of interest. This is an activity unlikely to be pursued by U.S. airconditioning manufacturers and again illustrates the need for properties standardization.

For the long term, beyond the 10 year horizon, there is significant research in place at national laboratories at MITI on development of third generation replacement refrigerants involving amine (nitrogen), sulfur, silicon and alcohol. To date some 50 new compounds have been synthesized by a variety of fluorination methods and are being subjected to environmental and toxicity tests (acute and sub-chronic). These programs were initiated in 1990 with a 5 year schedule and a 0.5 billion dollar budget. It is anticipated that, by 1995, several new refrigerant candidates will emerge for industry evaluation.

\section{LUBRICANTS RESEARCH}

Polyalkylene glycols (PAGs) are currently used with HFC-134a in automotive airconditioning systems. Autos built this year using HFC-134a will be using modified PAGs, with or without the EP additives for all compressor designs.

Polyolesters (POEs) are the preferred synthetic lubricants being tested for HFC refrigerants for all other applications (domestic refrigerators, commercial refrigeration, stationary air-conditioning, etc.). Several automotive compressor manufacturers are actively engaged in the testing of POEs. Hydrolytic stability of esters is a concern in Japan. Additives such as "acid catchers" are being tried and evaluated with success. 
Complex esters were chosen initially for improved miscibility at low temperatures but have hydrolytic stability. Hindered polyol esters are better from this point of view. Other additives for POE's under evaluation include antiwear, oxidation inhibitors and metal deactivators.

Regarding specifications for esters, there is consensus that the "total acid number" is the most important parameter; hydrolysis test, hydroxyl number and saponification number also of general interest. Instead of the standard "FLOC Point" (applicable with CFC 12 only), "insolubles" at $-40^{\circ} \mathrm{C}$ in $10 \%$ oil $/ 90 \%$ refrigerant will be the correct property definition. For refrigeration applications "none present" will be the value for "insolubles".

The major criteria used to select lubricants for alternative refrigerants are miscibility with the refrigerant, chemical and thermal stability, lubricity, hydrolytic stability, electric resistivity, compatibility with residual chlorine, and hygroscopicity. These concerns explain why, for automotive compressors in open systems, PAGs are being $\lrcorner$ sed.

There were no reported research efforts to use hydrocarbon lubricants such as mineral oils and alkyl benzene with HFC refrigerants. Carbonate type lubricants are still in the early stages of screening and development testing.

For reciprocating compressors, POEs, specially formulated in some cases, generally satisfy the performance and durability requirements. For rotary compressors, the extent of development work remaining varies between companies. Some have products with HFC 134a and formulated POEs and many are still in the process of solving the vane on roller lubricity problems. Not much information is available regarding screw, scroll and centrifugal compressors.

Equipment manufacturers who have more than one type of compressor design generally prefer one base stock ester and may have different additive packages for some types of compressors.

No lubricant other than carbonate based chemicals is being developed as a back-up for POEs. Although one lubricant supplier claimed to have developed a non-ester, nonPAG, non-carbonate lubricant, Japanese manufacturers had not evaluated the lubricant.

No company indicated any has plans for using ester lubricants with current refrigerants such as CFC-12, HCFC-22 and R-502.

The need to study organic materials, process materials, and cleaning agents (solvents) for compatibility with HFC's and esters was emphasized. Specifications for moisture level with esters are generally below $100 \mathrm{ppm}$. However, much lower levels $(20 \mathrm{ppm}$ to 40ppm) are being achieved in systems. 


\section{MATERIAL COMPATIBILITY AND LUBRICITY SCREENING}

Japanese air conditioning and refrigeration equipment manufacturers conduct materials compatibility tests, thermal stability tests and lubricity tests as preliminary steps to qualify alternative refrigerants and lubricants. In general, the compatibility and thermal stability tests are the same as are commonly used by U.S. manufacturers. Samples of motor materials, elastomers; plastics and metals are exposed to refrigerants and refrigerant-lubricants at elevated temperatures for extended times in sealed glass tubes or in stainless steel pressure vessels. Controlled amounts of oxygen and moisture are used to accelerate the instability mechanisms. Test conditions for materials compatibility ranged from $50^{\circ} \mathrm{C}\left(122^{\circ} \mathrm{F}\right)$ for 2 weeks to $150^{\circ} \mathrm{C}\left(302^{\circ} \mathrm{F}\right)$ for 1 week. Thermal stability tests for HFC refrigerants and lubricants were typically conducied at $120-150^{\circ} \mathrm{C}(248$ $302^{\circ} \mathrm{F}$ ) for 30 days. Properties measured before and after compatibility exposures included weight and dimensional changes and tensile and dielectric properties on motor materials. One manufacturer was also very concerned about the leakage current through magnet wire insulation and sheet insulation. They reported that the leakage current was much higher for HFC-134a and polyolester lubricant than for CFC-12 and mineral oil. High leakage current could possibly damage insulation materials over the long term.

Several types of tests are used to determine the lubricity of refrigerant-lubricant mixtures. All the Japanese equipment manufacturers visited use Falex-pin and vee block tests for preliminary screening. Some also use the Four Ball Test. Two manufacturers had designed and constructed lubricity test devices that simulated wear contacts in compressors at system conditions. These devices were used by the Japanese for fundamental studies that led to improvements in lubricants, additives and materials. For example, studies showed that the lubricity of HFC-134a and polyolesters were inferior to CFC-12 and mineral oil. The difference occurred because chlorine from CFC-12 reacts at the wear surface to form chlorides that act as solid lubricants. Since HFC-134a does not contain chlorine, additives are required to improve lubricity of the polyolesters. Since fluorine from HFC-134a reacts to form solid fluorides under extreme wear conditions, the fluorides are less effective as solid lubricants.

All Japanese equipment manufacturers visited have materials and chemistry laboratories that are well equipped to evaluate materials compatibility, thermal stability, and lubricity.

All equipment manufacturers were concerned about long term reliability, but none had developed accelerated compatibility tests to predict long-term life. Rather, they rely on compressor tests at accelerated conditions of higher pressures and temperatures for final qualification of materials and lubricants.

Several papers and panel discussions at the International Seminar on New Technology of Alternative Refrigerants, Lubricants and Material Compatibility discussed the plugging of capillary tubes in refrigerators operated with HFC-134a and polyolester lubricant. The cause was described as a combination of (1) the polyolester lubricant hydrolyzed to form 
polymers, acids and metal salts, (2) the acids from hydrolysis increase the number of wear particles that accumulates in the other sludge, (3) paraffin and bees' wax used to lubricate magnet wire is insoluble in polyolester lubricant and separates at the capillary tubes, and (4) residual process oils have low solubility in polyolester and separate at the capillary tubes.

The capillary tube plugging problem prompted the development of "improved" polyolesters by Japanese lubricant manufacturers. The "improved" polyolesters were claimed to have greater resistance to hydrolysis along with additives to neutralize acids. All Japanese equipment manufacturers visited now prefer the "improved" ester lubricants.

\section{NEW DESIGNS/RETROFITS}

\section{A. Retrofits}

There does not seem to be much experience with field conversions. Companies seem more likely to recommend replacement of equipment than conversion. Companies were concerned about warranties on conversions. Gas-fired absorption is being pushed as an option. One company stated that they would recommend that centrifugal chillers over 15 years old be replaced with absorption or HFC-134a or HCFC-123 machines and units less than 15 years be retrofitted to HCFC-123 or HFC-134a, as appropriate. Some companies indicated that they were recommending converting R-502 machines to HCFC-22.

The JRAIA has published a guideline for conversions of centrifugal chillers from CFC-11 to HCFC-123. One chiller was converted from CFC-11 to CFC-123 during January 1993.

Recovery of refrigerants is not mandatory at this time, although it is becoming common practice and some air-conditioning equipment manufacturers also manufacture recovery/recycling equipment.

There is no Japanese standard for the purity level of reclaimed refrigerant. Some refrigerant companies have a minimum purity level they will accept for reclaim. Extra charges will be assessed for reclaiming refrigerants with higher impurity levels.

\section{B. System Design}

The mini-split systems that are most common in Japan can require a large quantity of refrigerant per ton of cooling capacity due to the long runs between the outdoor and indoor units. Companies are taking steps to minimize refrigerant charge by using smaller tubing for heat exchangers and by placing the expansion 
valve in the outside unit so that smaller refrigerant lines can be used. Companies do not expect to use zeotrope refrigerants in these systems because of significant composition changes within the system.

One company anticipated that zeotropes will replace HCFC-22 using the Lorenz cycle. The super heat pump research shows that using the Lorenz cycle can double COP.

\section{OTHER OBSERVATIONS}

Most of the companies were asked "What is the role of the Japanese government with respect to incentives?" Although some of the companies did not seem to know, most said that the Japanese government is offering companies, especially smaller companies, a low interest loan fund to convert plants away from CFCs. One company said that even larger companies can use these funds for some applications such as, replacing CFC solvents used in the manufacturing process. There are also low interest loans to equipment owners to help convert away from CFCs. The government has not imposed a CFC tax, nor is recovery mandatory at this time.

The Japarese do not have the equivalent of ASHRAE 15 and 34 standards. Some companies stated that flammability requirements are covered by the high pressure gas law.

One company has developed a low temperature economical process for decomposing chlorinated organic compounds. The process will likely be used commercially to destroy CFCs.

\section{REFERENCES}

Calm, James M., Refrigerant Database, Paper presented at the 1992 International CFC and Halon Alternatives, Washington, DC, 29 September 1992 - 1 October 1992. 
Preface III

Acknowledgements V

Cooperating Organizations .......................................................................IX

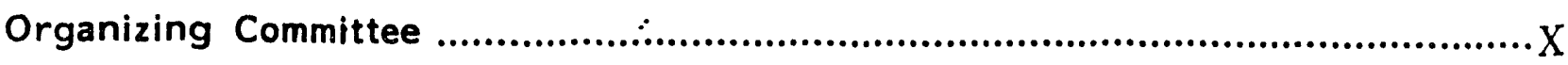

\section{TECHNICAL, SESSIONS}

\section{TECHNICAL SESSION 1}

Chair: Yoshinori Takaishi, Kanagawa Institute of Technology, Japan

1.1 Tsuyoshi Takaichi, Showa Denko K.K., Japan

Current Status of $R \& D$ for CFC Alternatives ............................... 3

1.2 Diana L. Klug, Du Pont Company, U.S.A. Near- and Long-Term Alternatives for Hydrochlorofluorocarbon 22 ( HCFC-22)

1.3 Kirk E. Davis and James N. Vinci, Lubrizol Performance Products Company, U.S.A. Formulation of Polyol Ester Lubricants for Use with HFC Refrigerants

\section{TECHNICAL SESSION 2}

Chair: Hiroyuki Sugiura, Zexel Corporation, Japan

2.1 Yoshitaka Natsume, Nippondenso Co., Ltd., Japan

Refrigerating Machine Lubricants for New Refrigerant.

2.2 Tsutomu Matsuzaki and Masao Akei, Calsonic Corp., Japan

The Friction and Wear Behaviour in Refrigerant Atmosphere.

\section{TECHNICAL SESSION 3}

Chair: Mark S. Menzer, Air-Conditioning and Refrigeration Institute, U.S.A.

3.1 Hans 0 . Spauschus, David R. Henderson and Dietrich $\mathbf{F}$. Huttenlocher, Spauschus Associates, Inc., U.S.A. Boundary Lubrication Properties of Alternative Working Fluids 
3.2 K. S. Sanvordenker, Tecumseh Products Company, U.S.A. Materials Compatibility Concerns for Refrigerator-Freezers A Historic Perspective and a Look to the Future

3.3 Poul Erik Hansen, Danfoss-Flensburg CmbH, Germany

On the Oil Selection Methodology for New Refrigerants for

Small Hermetic Compressors

\section{TECHNICAL SESSION}

Chair: Yukinobu Ikemoto, Mitsubishi Heavy Industries, Ltd., Japan

4.1 Naoki Tanaka, Mitsubishi Electric Corporation, Japan

Trends of Alternative Refrigerants in Refrigerating

Machines

4.2 Sonny G. Sundaresan, Copeland Corporation, U.S.A.

Commercial Refrigeration: The Challenges and the Issues

Regarding the Retrofit and New Equipment

4.3 Keiji Koike, Ebara Corporation, Japan

HCFC-123 Centrifugal Refrigeration Machine

4.4 G. Mozzon and P. Sansalvadore, ASPERA - Whirlpool Compressor

Operation, Italy

Reliability of Hermetic Compressors for R134a Appliances

\section{TECHNICAL SESSION 5}

Chair: Yoshiyuki Morikawa, Matsushita Electric Industrial Co., Ltd., Japan

5.1 John G. Johnson and Thomas E. Watson, SnyderGeneral Corporation, U.S.A.

Refrigerant-134a Compatibility with Centrifugal Chillers

5.2 Shigehiro Uemura, Daikin Industries, Ltd., Japan

Basic Requirements and Future Solutions of Air Conditioning

Units with Alternative Refrigerants - 1

5.3 Hisao Wakabayashi, Matsushita Electric Industrial Co., Ltd., Japan

Basic Requirements and Future Solutions of Air Conditioning

Units with Alternative Refrigerants - 2

5.4 Howard W. Sibley, Carrier Corporation, U.S.A. Oil Foaming Characteristics: The Forgotten Design Parameter with HFC-134a 
PANEL SESSIONS

PANEL SESSION 1: Development of New Refrigerating Lubricants

for Alternative Refrigerants

Chair: Shigeki Komatsuzaki, Hitachi, Ltd., Japan

Panelists :

Minoru Takagi, Idemitsu Kosan Co., Ltd., Japan

Takashi Kaimai, Kyodo Oil Technical Research Center Co., Ltd., Japan

Haruo Saito, Japan Sun Oil Co., Ltd., Japan

Motoshi Sunami, Nippon Oil Co., Ltd., Japan

Kinya Mizui, Mitsui Petrochemical Industries, Ltd., Japan

Tsuneyuki Nishizawa, ICI Japan Technical Centre, Japan

PANEL SESSION 2: Synthetic Lubricants Specifications

Chair: Soniny G. Sundaresan, Copeland Corporation, U.S.A.

Panelists :

Brian H. Carter, Wastrol International, U.K.

William E. Hagstrarid, Lubrizol Performance Products Compiny, U.S.A. Joosup Shim, Mobil Research $\varepsilon$ Development Corporation, U.S.A.

Michael Hughes, Allied-Signal Inc., U.S.A.

PANEL SESSION 3 : Materials Compatibility

Chair: Richard H. Ernst. The Trane Comapny, U.S.A.

Panelists :

Richard H. Ernst, The Trane Company, U.S.A.

Alan P. Cohen, UOP, U.S.A.

Richard C. Cavestri, Imagination Resources Inc., U.S.A.

Stewart Corr, ICl Chemicals \& Polymers Ltd., U.K.

PANEL SESSION 4: CFC Alternative Technologies Focusing on

Compressors for Domestic Refrigerators

Chair: Kiyoshige Yokoi, Matsushita Reírigeration Company, Japan

Panelists :

Naoya Kawakami, Sawafuji Electric Co., Ltd., Japan

Takeo Komatsubara, Sanyo Electric Co.. Ltd., Japan

Ren Ishidoya, Toshiba Corporation, Japan

Hiroaki Hata, Hitachi, Ltd.., Japan

Hideki Kawai, Matsushita Refrigeration Company, Japan

Kazutomo Asami, Mitsubishi Electric Corporation, Japan 


\section{APPENDIX B.}

\section{ARI Delegation}

Mr. Richard H. Ernst, The Trane Company

Mr. Howard W. Sibley, Carrier Corporation

Mr. S. Ganesan Sundaresan, Copeland Corporation

Mr. Thomas E. Watson, SnyderGeneral Corporation

Mr. Mark S. Menzer, Air-Conditioning and Refrigeration Institute

\section{Companies Visited}

Asahi Glass Research Center, Yokohama

Daikin Industries, Osaka

Hitachi, Ltd., Tokyo

Matsushita Electric Industrial Company, Ltd., Shiga

Ministry of International Trade and Industry (MITI), Tokyo

Mitsubishi Heavy Industry, Ltd., Tokyo

Showa Denko America, Inc., Tokyo

Toshiba Corporation Fuji Works, Hizuoka 
I
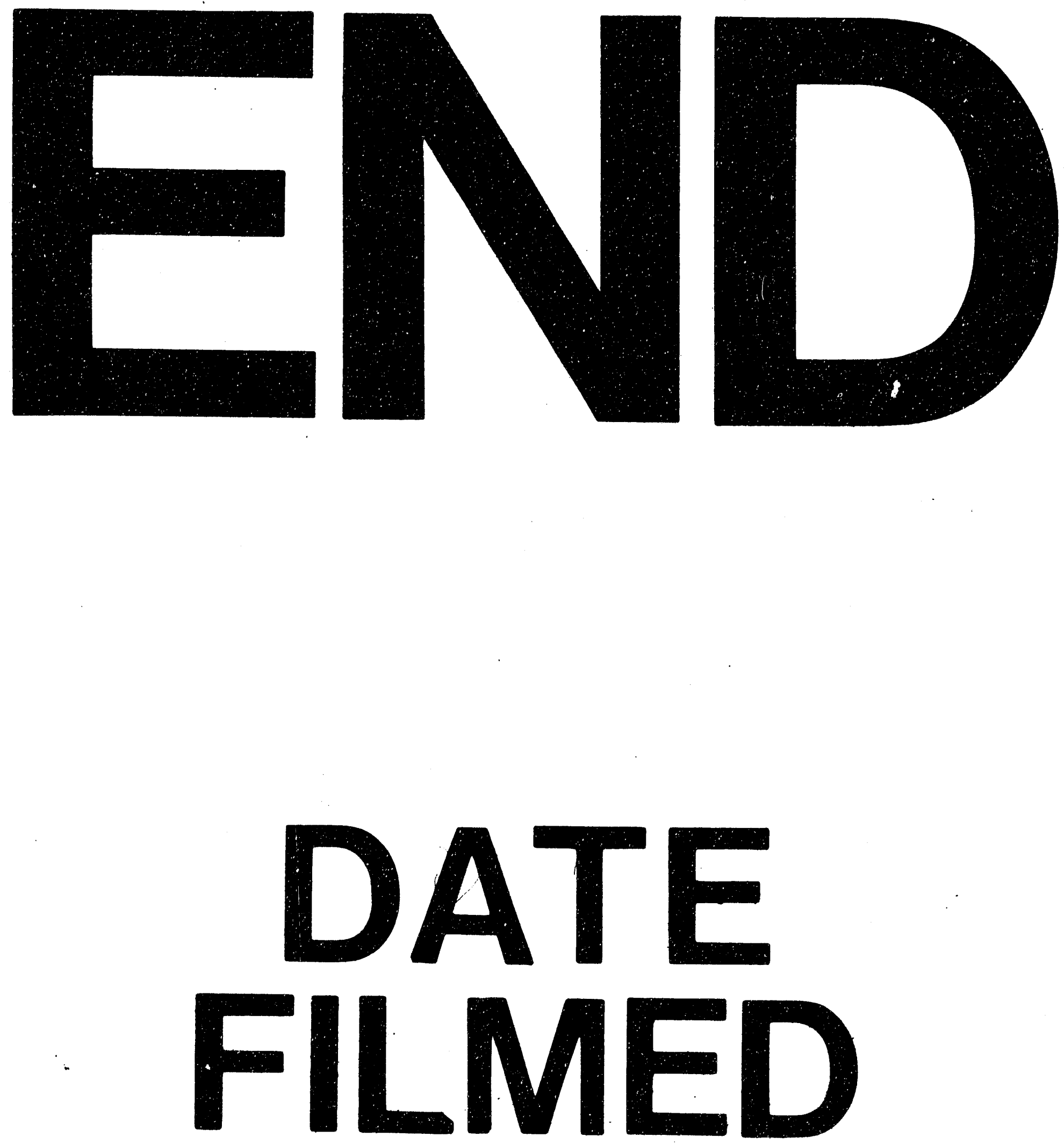

$\stackrel{\vec{z}}{\bar{\Xi}}$

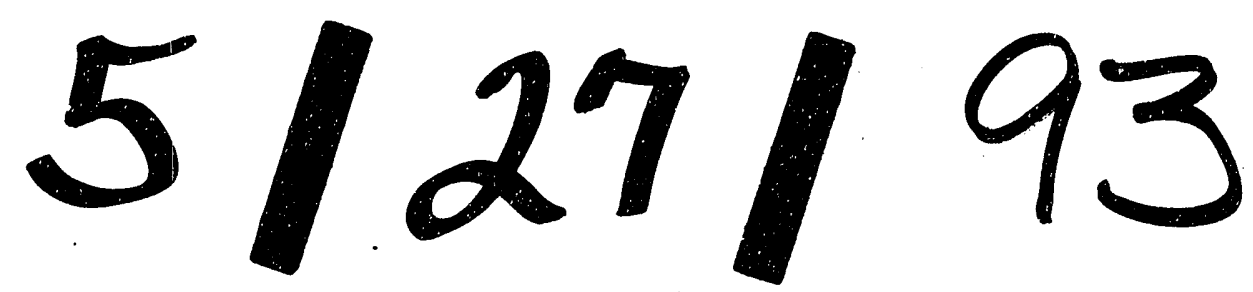


